\title{
A Real-Time PCR Assay for the Detection of Clavibacter michiganensis subsp. sepedonicus Based on the Cellulase A Gene Sequence
}

\author{
Neil C. Gudmestad, Ipsita Mallik, Julie S. Pasche, Nolan R. Anderson, and Kasia Kinzer, Department of Plant \\ Pathology, North Dakota State University, Fargo 58108
}

\begin{abstract}
Gudmestad, N. C., Mallik, I., Pasche, J. S., Anderson, N. R., and Kinzer, K. 2009. A real-time PCR assay for the detection of Clavibacter michiganensis subsp. sepedonicus based on the cellulase A gene sequence. Plant Dis. 93:649-659.

Clavibacter michiganensis subsp. sepedonicus, causal agent of bacterial ring rot (BRR) of potato (Solanum tuberosum), is a globally important quarantine pathogen that is managed in North America using zero tolerance regulations in the certified seed industry. C. michiganensis subsp. sepedonicus is well documented to cause symptomless infections in potato, contributing to its persistence in certified seed stocks. Reliable laboratory methods to detect symptomless infections with a high degree of sensitivity could assist in the reduction of inoculum in certified seed potato stocks. A real-time polymerase chain reaction (PCR) assay was developed using the cellulase A (CelA) gene sequence as the basis for primer design. CelA primers were specific to $C$. michiganensis subsp. sepedonicus grown in vitro and did not detect any other coryneform bacteria or potato pathogenic bacteria but did detect 69 strains of $C$. michiganensis subsp. sepedonicus. The CelA real-time PCR assay was more sensitive than immunofluorescence (IFA) and Cms50/72a PCR assays in detecting C. michiganensis subsp. sepedonicus in infected potato tuber cores blended with healthy tuber cores in simulated seed lot contamination experiments. CelA primers detected nonmucoid and mucoid strains with equivalent sensitivity. In naturally infected seed lots, CelA PCR primers also were more sensitive in detecting symptomless infections of C. michiganensis subsp. sepedonicus in seed tubers prior to planting compared to Cms50/72a PCR primers, IFA, and enzyme-linked immunosorbent assay. A real-time PCR format using the newly developed CelA primers proved to be a very robust detection tool for $C$. michiganensis subsp. sepedonicus with the added advantage of detecting only virulent strains of the ring rot bacterium.
\end{abstract}

Bacterial ring rot (BRR), caused by the gram-positive bacterium Clavibacter michiganensis subsp. sepedonicus, remains a threat to the potato (Solanum tuberosum) industry in North America. Although the disease occurs sporadically, serious outbreaks of BRR have occurred in a number of potato producing areas over the past several years in the United States and Canada. One of the key tactics for management of BRR is the use of certified seed that has been visually inspected for the disease. BRR is a highly regulated "zero tolerance" disease in the production of certified seed. No level of the disease is tolerated, and a certified seed field or seed lot is rejected if any plant or plant tissue infected with BRR is found during the inspection process.

Unfortunately, zero tolerance for BRR alone has been insufficient for long-term management of the disease since ring rot infections can remain symptomless or

Corresponding author: Neil C. Gudmestad

E-mail: Neil.Gudmestad@ndsu.edu

Accepted for publication 20 February 2009.

doi:10.1094/PDIS-93-6-0649

(C) 2009 The American Phytopathological Society latent $(8,33,43)$. A number of factors have been associated with the lack of BRR disease expression in potato, including the potato cultivar, strain of the bacterium, initial inoculum dose, and environmental conditions $(8,33,43,44)$. Additionally, $C$. michiganensis subsp. sepedonicus can persist for extended periods of time on contaminated potato production surfaces (42), allowing low levels of the bacterium to exist, and thereby increasing the potential of the pathogen to infect disease-free seed stocks. BRR symptom expression can vary from season to season among potato cultivars, and a number of cultivars have been identified in which visual inspections are inadequate for detection $(14,27,34,35)$. For this reason, postharvest testing has been implemented in several areas in an effort to reduce the risk of seedborne infections of $C$. michiganensis subsp. sepedonicus.

A number of tests have been developed to detect $C$. michiganensis subsp. sepedonicus with high sensitivity and specificity. The first tests developed were serologically based, with $C$. michiganensis subsp. sepedonicus-specific monoclonal antibodies utilized in immunofluorescent-antibody staining (IFA) (17) and enzyme-linked immunosorbent assays (ELISA) (18). Serological methods still are being refined using monoclonal antibodies developed against the ring rot pathogen (47). However, ELISA has been demonstrated to be ineffective in the detection of nonmucoid or nonfluidal strains of $C$. michiganensis subsp. sepedonicus (3). This phenomenon is thought to be due to the differences that exist in the exopolysaccharide between nonmucoid and mucoid strains of the pathogen (24). Although the impact of nonmucoid/nonfluidal strains on the global persistence of BRR in potato production is debatable, the development of nonserological methods for ring rot detection would be a critical step in the successful management of BRR.

More recently, DNA-based detection technology has been employed using a variety of methods including hybridization $(20,26,50)$, immunocapture $(5,36)$, and polymerase chain reaction (PCR) $(29,31$, $37,48,50,52,53)$. PCR is becoming more commonly used for detection of C. michiganensis subsp. sepedonicus, and a wide array of DNA and RNA primers have been developed specifically to detect it $(6,29,31$, $37,38,48,50,52)$. Although most C. michiganensis subsp. sepedonicus-specific primers were developed for a classical PCR format, some of these primers have been used successfully in a real-time format $(2,6,52,55)$. The three $C$. michiganensis subsp. sepedonicus-specific primer sets developed by Mills et al. (37), Cms50, Cms72, and Cms85, are perhaps the most commonly used in conventional PCR. However, of these three primer sets, $\mathrm{Cms} 85$ has been demonstrated to be less reliable and sensitive and is used less frequently than the other two primer sets (5).

PCR-based detection methods that target virulence genes have been useful in distinguishing virulent from avirulent forms of Streptomyces scabies (56). The mechanism of pathogenesis for $C$. michiganensis subsp. sepedonicus was initially thought to be the exopolysaccharide (EPS) that plugged the xylem tissue of potato plants (57); however, this was not universally accepted since nonmucoid and mucoid strains with equal virulence had EPS with substantially different biochemical characteristics (24). The involvement of a cellulase enzyme as a primary virulence determinant was suggested because of in vitro production (4) and electron microscopic studies that revealed large sections of xylem tissue that had been compromised enzymatically (N. C. Gudmestad, unpublished). Subsequent to the aforementioned 
studies, it was demonstrated that a cellulase enzyme produced by $C$. michiganensis subsp. sepedonicus was responsible for virulence of the pathogen in planta (45). The cellulase enzyme is encoded on the native plasmid $(22,28)$ described and designated pCS1 by Mogen and Oleson (40). The objective of the studies reported here was to develop $C$. michiganensis subsp. sepedonicus-specific primers based on the cellulase A gene sequence to be used in a real-time PCR.

\section{MATERIALS AND METHODS}

PCR assays. The first set of primers used in these studies to detect $C$. michiganensis subsp. sepedonicus is based on the Cms50 and Cms72 fragments (GenBank accession nos. AF001266 and AF001267, respectively) designed using subtraction hybridization of its genome (37). The forward and reverse primer sequences for $\mathrm{Cms} 72$ were modified from the original primer sequence for our realtime PCR format to facilitate binding of the probe and were designated $\mathrm{Cms} 72 \mathrm{a}$ (Table 1). Cms72 yields an amplicon size of $164 \mathrm{bp}$, while primer sets Cms50/72a amplify single-copy $C$. michiganensis subsp. sepedonicus-specific DNA fragments of 192 and 213 bp, respectively. For classical multiplex PCR with primers Cms50/72a, $0.25 \mu \mathrm{M}$ of each forward and reverse primer were added to the mix consisting of $1 \times$ polymerase buffer, $2 \mathrm{mM}$ $\mathrm{MgCl}_{2}, 0.5 \mathrm{mM}$ dNTP (Promega), 1.5 units of Amplitaq Gold polymerase (Applied Biosystems), and $2 \mu \mathrm{l}$ of template DNA in a $25-\mu$ reaction. The cycling conditions involved initial incubation for $5 \mathrm{~min}$ at $95^{\circ} \mathrm{C}$, followed by 10 cycles of $45 \mathrm{~s}$ at $94^{\circ} \mathrm{C}, 1 \mathrm{~min}$ at $60^{\circ} \mathrm{C}$, and $15 \mathrm{~s}$ at $72^{\circ} \mathrm{C}$, another 40 cycles of $45 \mathrm{~s}$ at $92^{\circ} \mathrm{C}, 40 \mathrm{~s}$ at $60^{\circ} \mathrm{C}$, and $20 \mathrm{~s}$ at $72^{\circ} \mathrm{C}$, and finally an extension at $72^{\circ} \mathrm{C}$ for $10 \mathrm{~min}$. The amplification with primer CelA was performed by adding $0.5 \mu \mathrm{M}$ of each forward and reverse primer to the mix consisting of $1 \times$ polymerase buffer, $1.5 \mathrm{mM} \mathrm{MgCl}_{2}, 0.2 \mathrm{mM}$ dNTP, 1 unit of Amplitaq Gold polymerase, and $2 \mu \mathrm{l}$ of template DNA in a 25$\mu \mathrm{l}$ reaction. The cycling conditions involved initial incubation for $5 \mathrm{~min}$ at $95^{\circ} \mathrm{C}$, followed by 40 cycles of $30 \mathrm{~s}$ at $92^{\circ} \mathrm{C}, 45 \mathrm{~s}$ at $60^{\circ} \mathrm{C}$, and $30 \mathrm{~s}$ at $72^{\circ} \mathrm{C}$, and finally an extension at $72^{\circ} \mathrm{C}$ for $7 \mathrm{~min}$.

Table 1. Real-time polymerase chain reaction oligonucleotide primer and fluorescent probes sequences for Cms50, Cms72a, and CelA

\begin{tabular}{ll}
\hline Primer/probe name & Sequence $\left(\mathbf{5}^{\prime} \mathbf{-} \mathbf{3}^{\prime}\right)$ \\
\hline Cms50F & GAGCGCGATAGAAGAGGAACTC \\
Cms50R & CCTGAGCAACGACAAGAAAAATATG \\
Cms72aF & CTACTTTCGCGGTAAGCAGTT \\
Cms72aR & GCAAGAATTTCGCTGCTATCC \\
Cms50 probe & [DFAM] TGAAGATGCGACATGGCTCCTCGGT [DBH1] \\
Cms72a probe & [DCY5] GATCGTGAATCCGAGACACGGTGACC [DBH2] \\
CelA-F & TCTCTCAGTCATTGTAAGATGAT \\
CelA-R & ATTCGACCGCTCTCAAA \\
CelA probe & [DHEX] TTCGGGCTTCAGGAGTGCGTGT [DBH2] \\
\hline
\end{tabular}

The fluorogenic probe specific for Cms50 was labeled with reporter dye 6carboxy-fluorescein (FAM) $(517 \mathrm{~nm}$ maximum emission) at the $5^{\prime}$ end, and the $3^{\prime}$ end was modified with the quencher dye BH1 (Table 1). Similarly, the probe specific for Cms72a was labeled with reporter dye Cy5 (667 nm maximum emission) at the $5^{\prime}$ end, and the $3^{\prime}$ end was modified with the quencher dye BH2 (Sigma Genosys) (Table 1). Real-time (TaqMan) PCR was performed in $0.2 \mathrm{ml}$ optical tube strips (Stratagene) using Stratagene Mx3005P QPCR system. The real-time PCR assay was performed in a $25-\mu$ reaction consisting of $4 \mu \mathrm{l}$ of template DNA, $1 \times$ FastStart Universal Probe Master, Rox (Roche), $\mathrm{Cms} 50 \mathrm{~F}$ and $\mathrm{Cms} 50 \mathrm{R}$ primers at a concentration of $0.4 \mu \mathrm{M}, \mathrm{Cms} 72 \mathrm{aF}$ and $\mathrm{Cms} 72 \mathrm{aR}$ primers at $1 \mu \mathrm{M}$, and the corresponding probes at $0.4 \mu \mathrm{M}$ and $0.6 \mu \mathrm{M}$, respectively. PCR grade water was added to a final volume of $25 \mu$ l. A two-step cycling protocol was used with an initial incubation of the mix at $95^{\circ} \mathrm{C}$ for $10 \mathrm{~min}$ followed by 40 cycles at $95^{\circ} \mathrm{C}$ for $30 \mathrm{~s}, 60^{\circ} \mathrm{C}$ for $45 \mathrm{~s}$, and $72^{\circ} \mathrm{C}$ for $30 \mathrm{~s}$ with data capture at the end of each $72^{\circ} \mathrm{C}$ incubation.

The second primer set, CelA-F and CelA-R, was designed based on the cellulase A gene sequence encoded by the native plasmid pCS1 of C. michiganensis subsp. sepedonicus (GenBank accession no. AY007311). The primers amplify a 150-bp region in the cellulase A gene sequence (Table 1). Transcription of the cellulase A gene is initiated at nucleotide 568 , with the promoter region running from nucleotide 566 to 575 (28). The CelA primer set amplifies from region 598 to 747. The fluorogenic probe specific for CelA was labeled with reporter dye Hex (553 $\mathrm{nm}$ maximum emission) at the $5^{\prime}$ end, and the $3^{\prime}$ end was modified with the quencher dye $\mathrm{BH} 2$ (Table 1). Real-time PCR was performed in a $25-\mu$ l reaction consisting of $2 \mu \mathrm{l}$ of template DNA, $0.8 \times$ FastStart Universal Probe Master, Rox (Roche), CelA-F and CelA-R primers at a concentration of $0.75 \mu \mathrm{M}$, and the probe at a concentration of $0.16 \mu \mathrm{M}$. PCR grade water was added to a final volume of $25 \mu \mathrm{l}$. The real-time PCR protocol was identical to that described for $\mathrm{Cms} 50 / 72 \mathrm{a}$ primer sets. A positive crossing threshold $(\mathrm{Ct})$ of 35 cycles was used in all experiments for

650 Plant Disease /Vol. 93 No. 6 all C. michiganensis subsp. sepedonicus primer sets to determine the presence of the organism. The MX4000v 1.00 to 3.00 algorithm software in Stratagene MX3005P was utilized to automatically calculate and adjust the baseline $\mathrm{Ct}$ value. Additionally, the master mixture for real-time PCR containing ROX (Roche Applied Sciences) was included to serve as internal control for data normalization.

Specificity of the CelA real-time PCR assay. The specificity of the CelA primers was determined initially using bacteria grown in vitro added to the PCR mix directly, with no DNA extraction procedure utilized by testing 69 strains of C. michiganensis subsp. sepedonicus randomly selected from our extensive culture collection (Table 2). The specificity of the CelA primers was determined also by testing non-C. michiganensis subsp. sepedonicus bacterial strains from our collection, including Clavibacter rathayi, $C$. tritici, Leifsonia xyli subsp. cynodontis, Corynebacterium matruchotti, Curtobacterium flaccufaciens, Pectobacterium carotovora subsp. atroseptica, Rhodococcus fascians, and Streptomyces scabies (Table 3). Additional specificity evaluations included the following subspecies of $C$. michiganensis: C. michiganensis subsp. insidiosus, $C$. michiganensis subsp. michiganensis, $C$. michiganensis subsp. nebraskensis, and $C$. michiganensis subsp. tessellarius (Table 3). All specificity experiments were performed twice.

Sensitivity of Cms50/72a and CelA PCR using in vitro $C$. michiganensis subsp. sepedonicus. The sensitivity of $\mathrm{CelA}$ and Cms50/72a primers were compared using classical and real-time PCR assays. Bacterial strain OFF-1 was cultured in liquid nutrient broth yeast extract medium (NBY) for 24 to $48 \mathrm{~h}$ at room temperature and adjusted to an optical density of 0.1 at $560 \mathrm{~nm}$, corresponding to approximately $1 \times 10^{8}$ cells $/ \mathrm{ml}$, and subsequently serially diluted 10 -fold using molecular biology grade water. In addition to this, total genomic DNA was extracted from a 48-h culture of bacterial strain OFF-1 according to manufacturer's specifications (Wizard Genomic DNA purification kit, Promega). The final DNA concentration was adjusted to $10 \mathrm{ng} / \mu \mathrm{l}$ and then serially diluted 10 -fold with water. Both bacterial cells and purified DNA were tested using CelA and Cms50/72a PCR assays performed as previously described to determine if any reduction in sensitivity occurs when DNA is not extracted. All sensitivity experiments were performed twice.

Sensitivity of CelA real-time PCR using controlled $C$. michiganensis subsp. sepedonicus tuber infections. Several experiments were conducted to compare diagnostic methods for detecting C. michiganensis subsp. sepedonicus in simulated BRR-infected seed lots. The objective of 
these experiments was to artificially produce asymptomatic but $C$. michiganensis subsp. sepedonicus-infected seed lots. Infected tubers were produced by inoculating seed pieces freshly cut from certified seed-tubers cv. Russet Burbank. Seed pieces were vacuum infiltrated with $1 / 4$ strength nutrient broth containing either mucoid or nonmucoid $C$. michiganensis subsp. sepedonicus suspension of $10^{8}$ or $10^{4}$ cells $/ \mathrm{ml}$. Tubers were placed into a desiccator, broth was added to ensure complete coverage of all seed pieces, and a vacuum was applied and maintained at 103 $\mathrm{kPa}$ in the desiccator for $15 \mathrm{~min}$. Tubers subsequently were removed and allowed to dry on the bench top overnight. Twentyfive seed pieces were planted in 9-m rows in late May in 2005, 2006, and 2007. Fertilizer, insecticides, and fungicides were applied as necessary throughout the growing season. Tubers were harvested in early October in all 3 years, 125 to 130 days after planting. Approximately 20 to 30 asymptomatic tubers were selected from plants with foliar symptoms of BRR for use in evaluating existing and experimental diagnostic assays.

From each infected tuber selected, as well as each infection-free tuber, an approximately $1-\mathrm{g}$ core was excised from the stem end of the tuber using a sterilized common apple corer as previously described (19). One infected tuber core was combined with infection-free tuber cores, diluted $1: 2$ in sterile water, and shaken for 16 to $20 \mathrm{~h}$. Aliquots collected from the resulting soak solutions were used in analyses to mimic as closely as possible standard protocols followed by certification agencies in which 200 tuber core lots are processed. In the initial preliminary trial performed in 2005, asymptomatic but infected tubers, as confirmed by IFA described below, were blended with healthy tubers in ratios from one infected tuber per 199 healthy tubers $(1 / 200)$ to 10 infected tubers blended with 190 healthy tubers (10/200). In subsequent experiments, C. michiganensis subsp. sepedonicusinfected tubers with several population density levels were blended with healthy tubers in ratios of $1 / 100,1 / 200$, and $1 / 400$. In all experiments, the soak liquid from $C$. michiganensis subsp. sepedonicus-free cores was used as negative controls for all assays as well as to make the dilutions from $1: 100$ to $1: 200$ and $1: 400$, as each infected core could only be soaked once. The PCR was performed on various dilutions of tuber soak fluids to rule out the possibility of PCR inhibition due to compounds originating from host tissue. All IFA, ELISA, and PCR assays were performed twice.

The C. michiganensis subsp. sepedonicus population density in each asymptomatic tuber was determined using IFA before being used to blend with healthy potato tubers as previously described (3).
Table 2. Clavibacter michiganensis subsp. sepedonicus isolate designation and real-time polymerase chain reaction with primers Cms50/72a and CelA

\begin{tabular}{|c|c|c|c|c|c|}
\hline Isolate designation & Geographic origin & Source & Cms50/72a & CelA & pCS1 $^{a}$ \\
\hline 5 & Unknown & NDSU collection & + & + & nd \\
\hline 001 & South Dakota & NDSU collection & + & + & nd \\
\hline 002, Wi2 & Wisconsin & NDSU collection & + & + & nd \\
\hline 0021, Wi2 & Wisconsin & NDSU collection & + & + & nd \\
\hline $002 \mathrm{~s}, \mathrm{Wi} 2$ & Wisconsin & NDSU collection & + & + & nd \\
\hline 003 & South Dakota & NDSU collection & + & + & nd \\
\hline 004 & South Dakota & NDSU collection & + & + & nd \\
\hline 005 & South Dakota & NDSU collection & + & + & nd \\
\hline 076-10 & Minnesota & NDSU collection & + & + & nd \\
\hline $075-14$ & Wisconsin & NDSU collection & + & + & nd \\
\hline $084-3$ & Idaho & NDSU collection & + & + & nd \\
\hline $087-2$ & Idaho & NDSU collection & + & + & nd \\
\hline $087-24$ & Idaho & NDSU collection & + & + & nd \\
\hline 096A & North Dakota & NDSU collection & + & + & nd \\
\hline 097A & North Dakota & NDSU collection & + & + & nd \\
\hline 099A & North Dakota & NDSU collection & + & + & nd \\
\hline $100 \mathrm{~A}$ & North Dakota & NDSU collection & + & + & nd \\
\hline $102-1$ & Idaho & NDSU collection & + & + & nd \\
\hline 103 & North Dakota & NDSU collection & + & + & nd \\
\hline 104 & North Dakota & NDSU collection & + & + & nd \\
\hline $116-1-1$ & Idaho & NDSU collection & + & + & nd \\
\hline $116-6-5$ & Idaho & NDSU collection & + & + & nd \\
\hline $116-11-3$ & Idaho & NDSU collection & + & + & nd \\
\hline $116-16-1$ & Idaho & NDSU collection & + & + & nd \\
\hline $116-19-3$ & Idaho & NDSU collection & + & + & nd \\
\hline $116-24-3$ & Idaho & NDSU collection & + & + & nd \\
\hline $117-6$ & Washington & NDSU collection & + & + & nd \\
\hline 128 & North Dakota & NDSU collection & + & + & nd \\
\hline 135 & North Dakota & NDSU collection & + & + & nd \\
\hline 136 & North Dakota & NDSU collection & + & + & nd \\
\hline 137 & North Dakota & NDSU collection & + & + & nd \\
\hline 141 & Unknown & NDSU collection & + & + & nd \\
\hline $151-3$ & North Dakota & NDSU collection & + & + & nd \\
\hline 1921.3 & North Dakota & NDSU collection & + & + & nd \\
\hline AS-1 & Minnesota & NDSU collection & + & + & nd \\
\hline AS-1-R & Minnesota & NDSU collection & + & + & nd \\
\hline ATCC9850 & New York & ATCC & + & + & E \\
\hline ATCC 33113 & Canada & ATCC & + & + & E \\
\hline BETA1230 & North Dakota & NDSU collection & + & + & nd \\
\hline BJ19 & Oregon & NDSU collection & + & + & nd \\
\hline BRR7 & Brit Columbia & S. De Boer & + & + & $\mathrm{E}$ \\
\hline COL 1-B & North Dakota & NDSU collection & + & + & nd \\
\hline COLO 18 & Colorado & NDSU collection & + & + & nd \\
\hline $\mathrm{CS} 3 \mathrm{M}$ & Alberta & S. De Boer & + & + & $\mathrm{E}$ \\
\hline CS3NM & Alberta & S. De Boer & + & + & $\mathrm{E}$ \\
\hline CS3R & Alberta & S. De Boer & + & + & $\mathrm{E}$ \\
\hline CS3RC & Alberta & S. De Boer & + & + & nd \\
\hline CS5 & New York & S. De Boer & + & + & E \\
\hline CS14 (14) & Montana & S. Slack & + & - & - \\
\hline CS16 & New Brunswick & S. De Boer & + & + & E \\
\hline CS17 & Maine & S. De Boer & + & + & E \\
\hline CS20 & Wisconsin & S. Slack & + & + & I \\
\hline CS106 & W. Virginia & S. De Boer & + & + & I \\
\hline CSCA & California & A. Vidaver & + & + & E \\
\hline CSIDNM1 & Idaho & D. Clarke & + & + & $\mathrm{E}$ \\
\hline CSIDNM2 & Idaho & D. Clarke & + & + & nd \\
\hline CSMT & Montana & A. Vidaver & + & + & $\mathrm{E}$ \\
\hline CSSS-43 & Wisconsin & S. Slack & + & + & $\mathrm{E}$ \\
\hline CSSS-44 & Wisconsin & S. Slack & + & + & $\mathrm{E}$ \\
\hline INM-1 & Idaho & D. Clarke & + & + & nd \\
\hline NZ2531 & Sweden & PDDCC & + & + & E \\
\hline NZ2532 & Canada & PDDCC & + & + & $\mathrm{E}$ \\
\hline NZ2534 & New York & PDDCC & + & + & E \\
\hline NZ2535 & Canada & PDDCC & + & + & I \\
\hline NZ2537 & U.S.A. & PDDCC & + & + & $\mathrm{E}$ \\
\hline OFF & North Dakota & NDSU collection & + & + & nd \\
\hline P45 & Unknown & S. De Boer & + & - & - \\
\hline R1 & Brit Columbia & S. De Boer & + & + & I \\
\hline R2 & Brit Columbia & S. De Boer & + & + & I \\
\hline R3 & Brit Columbia & S. De Boer & + & + & I \\
\hline R4 & Brit Columbia & S. De Boer & + & + & I \\
\hline R5 & Brit Columbia & S. De Boer & + & + & I \\
\hline
\end{tabular}

a Presence of pCS1 plasmid is denoted as episomal (E), chromosomally integrated (I), absent (-), or was not determined (nd) (41). 
Each asymptomatic and presumed infected tuber selected was aseptically crosssectioned approximately $2.5 \mathrm{~cm}$ from the stem end, and a 1-g section of vascular tissue was extracted. Vascular tissue sections were diluted in $1 \mathrm{ml}$ of sterile phosphate buffered saline (PBS), resulting in a $1: 2$ dilution, and manually crushed to release bacterial cells. Two 10-fold serial dilutions were performed subsequently in PBS and added to individual wells of an 18-well microscope slide. Each well was stained using monoclonal antibody 9A1 mouse anti-C. michiganensis subsp. sepedonicus (17) and goat anti-mouse IgG and IgM polyclonal fluorescent labeled antibody following methods provided by Agdia Inc. (Elkhart, IN). A minimum of 10 high-powered $(\times 1,500)$ microscope fields (MF) were examined for the presence of fluorescent cells having the size and shape typical of $C$. michiganensis subsp. sepedonicus for each dilution well. The number of immunofluorescent units (IFU) was converted quantitatively and expressed as IFU/g tuber fresh weight (3). Vascular tissue sections were also tested using CelA PCR to confirm that cells visualized by IFA were not serological cross-reactors. Additionally, asymptomatic tubers from BRR-infected potato plants that produced a negative IFA reaction were tested with real-time PCR using Cms50/72a and CelA primers to determine if the tubers were healthy or latently infected with $C$. michiganensis subsp. sepedonicus. One or two tubers each of mucoid and nonmucoid, high $\left(>10^{7} \mathrm{IFU} / \mathrm{g}\right)$, moderate $\left(10^{6}\right.$ to $10^{7}$ IFU/g), and low $\left(<10^{5} \mathrm{IFU} / \mathrm{g}\right)$ infection levels were subsequently selected for use in the simulated BRR-contaminated seed lot trials. In 2007, only IFA-negative but PCR-positive tubers, indicating a symptomless infection of $C$. michiganensis subsp. sepedonicus, were used for further experiments to represent a low level of infection. Healthy tubers were selected from certified seed cv. Russet Burbank, processed as described above and confirmed by real-time PCR to be free from $C$. michiganensis subsp. sepedonicus before being blended with asymptomatic tubers or used as healthy controls.

ELISA was performed using capture by mouse monoclonal antibody $1 \mathrm{H} 3$ (18) in a double antibody sandwich (DAS) with detection by a polyclonal antibody labeled with alkaline phosphatase following provided protocols (Agdia). Aliquots of soak liquid representing each sublot of tuber composites were tested in triplicate wells on separate ELISA plates. Enzyme substrate was allowed to develop for $40 \mathrm{~min}$ before absorbance values were taken. Absorbance values $(405 \mathrm{~nm})>0.2$ were considered positive for the detection of $C$. michiganensis subsp. sepedonicus.

Commercial seed lot testing. In addition to controlled experiments using simulated C. michiganensis subsp. sepedonicus
Table 3. Bacterial name designation and real-time polymerase chain reaction (PCR) with primers Cms50/72a and CelA

\begin{tabular}{|c|c|c|c|c|c|}
\hline Bacterial name & $\begin{array}{l}\text { Isolate } \\
\text { designation }\end{array}$ & $\begin{array}{l}\text { Geographic } \\
\text { origin }\end{array}$ & Source & Cms50/72a ${ }^{a}$ & CelA \\
\hline \multicolumn{6}{|c|}{ Clavibacter michiganensis subsp. insidiosus } \\
\hline & 0.0239 & Unknown & L. Clafin & - & - \\
\hline & ATCC10253 & Kansas & ATCC & - & - \\
\hline & ATCC33114 & Unknown & ATCC & - & - \\
\hline & CI-4 & Unknown & S. De Boer & - & - \\
\hline & CI102B & Colorado & S. De Boer & - & - \\
\hline & CIAW81-3 & Colorado & S. De Boer & - & - \\
\hline & CILETH & Colorado & S. De Boer & - & - \\
\hline & CIN & Unknown & S. De Boer & - & - \\
\hline & CIN53 & Colorado & S. De Boer & - & - \\
\hline & NZ2611 & U.K. & PDDCC & - & - \\
\hline & NZ2621 & U.S.A. & PDDCC & - & - \\
\hline & NZ2948 & New Zealand & PDDCC & - & - \\
\hline & NZ3567 & Australia & PDDCC & - & - \\
\hline & NZ3619 & Australia & PDDCC & - & - \\
\hline & NZ3983 & U.S.A. & PDDCC & - & - \\
\hline & NZ4191 & New Zealand & PDDCC & - & - \\
\hline & NZ4543 & Unknown & PDDCC & - & - \\
\hline & NZ6565 & New Zealand & PDDCC & - & - \\
\hline \multicolumn{6}{|c|}{ Clavibacter michiganensis subsp. michiganensis } \\
\hline & 0.01104 & Kansas & L. Clafin & - & - \\
\hline & ATCC4450 & Unknown & ATCC & - & - \\
\hline & ATCC7430 & Unknown & ATCC & - & - \\
\hline & ATCC10202 & Unknown & ATCC & - & - \\
\hline & ATCC14456 & Italy & ATCC & - & - \\
\hline & NZ0549 & New Zealand & PDDCC & - & - \\
\hline & NZ1436 & New Zealand & PDDCC & - & - \\
\hline & NZ1808 & New Zealand & PDDCC & - & - \\
\hline & NZ1811 & New Zealand & PDDCC & - & - \\
\hline & NZ2355 & New Zealand & PDDCC & - & - \\
\hline & NZ2539 & South Africa & PDDCC & - & - \\
\hline & NZ2541 & U.K. & PDDCC & - & - \\
\hline & NZ2545 & Sicily & PDDCC & - & - \\
\hline & NZ2550 & Hungary & PDDCC & - & - \\
\hline & NZ2551 & Brazil & PDDCC & - & - \\
\hline & NZ5026 & U.S.A. & PDDCC & - & - \\
\hline & NZ6726 & New Zealand & PDDCC & - & - \\
\hline \multicolumn{6}{|c|}{ Clavibacter michiganensis subsp. nebraskensis } \\
\hline & 0.01105 & Colorado & L. Clafin & nd & - \\
\hline & 0.01106 & Kansas & L. Clafin & nd & - \\
\hline & 0.01118 & Kansas & L. Clafin & nd & - \\
\hline & 0.01119 & Kansas & L. Clafin & nd & - \\
\hline & 0.01120 & Kansas & L. Clafin & nd & - \\
\hline & ATCC27794 & Nebraska & ATCC & nd & - \\
\hline & ATCC27822 & Nebraska & ATCC & - & - \\
\hline & CNEB & Nebraska & A. Vidaver & nd & - \\
\hline & CNEB 1-1 & Nebraska & A. Vidaver & - & - \\
\hline & NZ3294 & U.S.A. & PDDCC & nd & - \\
\hline & NZ3299 & U.S.A. & PDDCC & nd & - \\
\hline & NZ3300 & U.S.A. & PDDCC & nd & - \\
\hline & NZ3303 & U.S.A. & PDDCC & nd & - \\
\hline & NZ5366 & U.S.A. & PDDCC & - & - \\
\hline & NZ5367 & U.S.A. & PDDCC & - & - \\
\hline & NZ5368 & U.S.A. & PDDCC & - & - \\
\hline & NZ5369 & U.S.A. & PDDCC & - & - \\
\hline \multicolumn{6}{|c|}{ Clavibacter michiganensis subsp. tessellarius } \\
\hline & 0.01122 & Nebraska & L. Clafin & - & - \\
\hline & NZ7220 & Unknown & PDDCC & nd & - \\
\hline & NZ7221 & Unknown & PDDCC & nd & - \\
\hline & NZ7222 & Unknown & PDDCC & nd & - \\
\hline & NZ7223 & Unknown & PDDCC & nd & - \\
\hline & NZ7224 & Unknown & PDDCC & nd & - \\
\hline & NZ7225 & Unknown & PDDCC & nd & - \\
\hline & NZ7226 & Unknown & PDDCC & nd & - \\
\hline & NZ7227 & Unknown & PDDCC & nd & - \\
\hline & NZ7228 & Unknown & PDDCC & nd & - \\
\hline & NZ7229 & Unknown & PDDCC & nd & - \\
\hline \multicolumn{6}{|c|}{ (Continued on next page) } \\
\hline
\end{tabular}

a Real-time PCR was negative (-) or not determined (nd). 
contamination rates described above, certified seed lots from North Dakota and Minnesota, known to have been previously exposed to bacterial ring rot infections, also were evaluated with all serological and PCR-based detection methods to compare detection efficiency. The certified seed lots were tested using fresh tuber material processed as previously described (19). The naturally infected seed lots were indexed in the laboratory using 2,000 to 4,400 tubers/seed lot, and all detection methods were applied to tuber cores processed into 200 tuber composites. All serological assays were performed as described above. Positive thresholds for IFA and ELISA were based on international standards (1). For IFA, a minimum of $30 \mathrm{MF}$ were examined and the test was considered positive if the average IFUs (fluorescing cells with characteristic size and shape of C. michiganensis subsp. sepedonicus) were equal to or greater than 5 IFU/MF. For ELISA, absorbance values $(405 \mathrm{~nm})>0.2$ were considered positive.

Seed lots tested for $C$. michiganensis subsp. sepedonicus were monitored the following growing season in those instances where the seed was planted commercially. Symptoms of bacterial ring rot were quantified for the incidence of ring rot by one of the authors (N. C. Gudmestad). The percentage of the disease was determined by scoring a minimum of 1,000 plants per field from 31 July to 11 August 2006. Randomly selected plants scored as being presumptively symptomatic for BRR were removed from the field and tested in the laboratory for the presence of $C$. michiganensis subsp. sepedonicus using CelA PCR to confirm the visual field diagnosis.

Statistical analysis. The parameter estimates of slope and intercept of the lines resulting from the regression analysis of threshold cycle and either DNA (ng/ml) or C. michiganensis subsp. sepedonicus cells/ml using $\mathrm{Cms} 50$ and $\mathrm{Cms} 72$ a primers were compared to the lines resulting from CelA primers. The line resulting from evaluation using CelA primers was used as a reference for analysis.

\section{RESULTS}

CelA primers detected all strains of $C$. michiganensis subsp. sepedonicus in our culture collection except plasmid negative strains P45 and CS14 (Table 2) and did not detect other bacterial strains (Table 3). CelA primers did not detect Clavibacter rathayi, C. tritici, Leifsonia xyli subsp. cynodontis, Corynebacterium matruchotti, Curtobacterium flaccufaciens, Erwinia carotovora subsp. atroseptica, Rhodococcus fascians, Streptomyces scabies, or other subspecies of Clavibacter michiganensis such as C. michiganensis subsp. insidiosus, C. michiganensis subsp. michiganensis, C. michiganensis subsp. nebraskensis, and $C$. michiganensis subsp. tessellarius.
Table 3. (Continued from preceding page)

\begin{tabular}{|c|c|c|c|c|c|}
\hline Bacterial name & $\begin{array}{l}\text { Isolate } \\
\text { designation }\end{array}$ & $\begin{array}{l}\text { Geographic } \\
\text { origin }\end{array}$ & Source & Cms50/72a ${ }^{a}$ & CelA \\
\hline \multicolumn{6}{|c|}{ Clavibacter rathayi } \\
\hline & ATCC13659 & U.K. & ATCC & - & - \\
\hline & NZ2572 & New Zealand & PDDCC & nd & - \\
\hline & NZ2573 & New Zealand & PDDCC & nd & - \\
\hline & NZ2574 & New Zealand & PDDCC & nd & - \\
\hline & NZ2575 & New Zealand & PDDCC & nd & - \\
\hline & NZ2576 & New Zealand & PDDCC & nd & - \\
\hline & NZ2577 & New Zealand & PDDCC & nd & - \\
\hline & NZ2579 & Scotland & PDDCC & nd & - \\
\hline \multicolumn{6}{|l|}{ Clavibacter tritici } \\
\hline & NZ2623 & India & PDDCC & - & - \\
\hline & NZ2624 & Egypt & PDDCC & nd & - \\
\hline & NZ2626 & Egypt & PDDCC & nd & - \\
\hline & NZ2627 & India & PDDCC & nd & - \\
\hline & NZ2628 & Iran & PDDCC & nd & - \\
\hline \multicolumn{6}{|c|}{ Clavibacter xyli subsp. cynodontis } \\
\hline & FB-1 & Unknown & M. Davis & nd & - \\
\hline & TB2B & Unknown & M. Davis & - & - \\
\hline \multicolumn{6}{|c|}{ Corynebacterium sp. } \\
\hline & NZ6306 & Australia & PDDCC & nd & - \\
\hline & NZ6307 & Australia & PDDCC & nd & - \\
\hline & NZ6308 & Australia & PDDCC & nd & - \\
\hline & NZ6309 & Australia & PDDCC & nd & - \\
\hline & NZ6310 & Australia & PDDCC & nd & - \\
\hline & NZ6311 & Australia & PDDCC & nd & - \\
\hline & NZ6790 & New Zealand & PDDCC & nd & - \\
\hline & NZ6792 & New Zealand & PDDCC & nd & - \\
\hline & NZ6793 & New Zealand & PDDCC & nd & - \\
\hline \multicolumn{6}{|c|}{ Corynebacterium matruchotii } \\
\hline & ATCC14264 & U.S.A. & ATCC & nd & - \\
\hline \multicolumn{6}{|c|}{ Curtobacterium flaccumfaciens } \\
\hline & 0.01102 & Nebraska & M. Schuster & nd & - \\
\hline & ATCC6887 & Unknown & ATCC & nd & - \\
\hline & CFACCV3 & Unknown & J. Venette & nd & - \\
\hline & CFLAC2A & Unknown & J. Venette & nd & - \\
\hline \multicolumn{6}{|c|}{ Curtobacterium flaccumfaciens pv. betae } \\
\hline & ATCC 13437 & Unknown & ATCC & nd & - \\
\hline & NZ2591 & U.K. & PDDCC & nd & - \\
\hline & NZ2592 & U.K. & PDDCC & nd & - \\
\hline & NZ2593 & U.K. & PDDCC & nd & - \\
\hline & NZ2595 & U.K. & PDDCC & nd & - \\
\hline & NZ4735 & U.K. & PDDCC & nd & - \\
\hline & NZ4736 & U.K. & PDDCC & nd & - \\
\hline & NZ4737 & U.K. & PDDCC & nd & - \\
\hline & NZ7458 & Brazil & PDDCC & nd & - \\
\hline \multicolumn{6}{|c|}{ Curtobacterium flaccumfaciens pv. flaccumfaciens } \\
\hline & NZ2580 & U.S.A. & PDDCC & nd & - \\
\hline & NZ2581 & U.S.A. & PDDCC & nd & - \\
\hline & NZ2582 & Romania & PDDCC & nd & - \\
\hline & NZ2583 & Unknown & PDDCC & nd & - \\
\hline & NZ2584 & Hungary & PDDCC & nd & - \\
\hline & NZ2585 & Germany & PDDCC & nd & - \\
\hline & NZ2588 & U.S.A. & PDDCC & nd & - \\
\hline & NZ2590 & U.S.A. & PDDCC & nd & - \\
\hline & NZ3495 & Netherlands & PDDCC & nd & - \\
\hline & NZ5370 & U.S.A. & PDDCC & nd & - \\
\hline & NZ5371 & U.S.A. & PDDCC & nd & - \\
\hline & NZ5372 & U.S.A. & PDDCC & nd & - \\
\hline & NZ5373 & U.S.A. & PDDCC & nd & - \\
\hline \multicolumn{6}{|c|}{ Curtobacterium flaccumfaciens pv. oortii } \\
\hline & $0.06-83-70-\mathrm{a}$ & Netherlands & G. Secor & nd & - \\
\hline & NZ2632 & Netherlands & PDDCC & nd & - \\
\hline & NZ3497 & Netherlands & PDDCC & nd & - \\
\hline & NZ3498 & U.K. & PDDCC & nd & - \\
\hline & NZ3499 & U.K. & PDDCC & nd & - \\
\hline \multicolumn{6}{|c|}{ Curtobacterium flaccumfaciens pv. poinsettiae } \\
\hline & NZ2561 & U.S.A. & PDDCC & nd & - \\
\hline & NZ2563 & U.S.A. & PDDCC & nd & - \\
\hline & NZ2564 & U.S.A. & PDDCC & nd & - \\
\hline & & & & (Continued & ext pag \\
\hline
\end{tabular}


The sensitivity of the CelA primers was higher in detecting $C$. michiganensis subsp. sepedonicus bacterial cells in classical PCR compared to Cms50/72a (Fig. $1 \mathrm{~A}$ and $\mathrm{C}$ ). CelA detected a population density of $10^{4}$ cells $/ \mathrm{ml}$, while the Cms50/72a detection limit was $10^{5}$ cells $/ \mathrm{ml}$. CelA real-time PCR was also more sensitive in detecting the cells compared to Cms50/72a (Fig. 2A). Results from regression analysis comparing realtime PCR of bacterial cells of C. michiganensis subsp. sepedonicus using Cms50, $\mathrm{Cms} 72 \mathrm{a}$, and CelA primers provide statistical support for the observed increased sensitivity. When compared to CelA, lines generated by $\mathrm{Cms50}(P=0.0004)$ and Cms72a $(P=0.0002)$ were significantly different than the line generated by CelA primers (Fig. 2A). These differences were due to an increase in both the y-intercept (Cms50 $P=0.0004$, Cms72a $P<0.0001)$ and the slope (Cms50 $P=0.0126, \mathrm{Cms} 72 \mathrm{a}$ $P=0.0004)$ of the lines (Fig. 2B). The CelA and Cms72a primer did not differ in sensitivity when comparing purified DNA of plasmid positive C. michiganensis subsp. sepedonicus strain OFF-1 in either classical PCR (Fig. 1B and D) or real-time
PCR (Fig. 2B). The line generated by Cms72a for bacterial cells was not significantly different than that generated by CelA $(P=0.5823)$. The regression line resulting from $\mathrm{Cms} 50$ was significantly different than CelA $(P=0.0008)$, both the slope $(P=0.0048)$ and intercept $(P=$ 0.0002 ) contributed to this difference. Four 150-bp amplicons resulting from amplification using CelA primers were cloned into pGEMT Easy (Promega) and sequenced for identity confirmation. These amplicons displayed $100 \%$ homology among them as well as with the published C. michiganensis subsp. sepedonicus cellulase A gene sequence (AY007311.1) from GenBank.

In real-time PCR assays, CelA primers were more sensitive than other detection methods in detecting $C$. michiganensis subsp. sepedonicus-infected cores that were blended with healthy tuber cores in preliminary experiments using simulated contamination rates. The CelA primers were capable of detecting two infected cores blended with 198 healthy cores, while the limit of detection in these experiments for IFA and Cms50/72a primers was 10 infected cores in 190 healthy.

Table 3. (Continued from preceding page)

\begin{tabular}{|c|c|c|c|c|c|}
\hline Bacterial name & $\begin{array}{l}\text { Isolate } \\
\text { designation }\end{array}$ & $\begin{array}{l}\text { Geographic } \\
\text { origin }\end{array}$ & Source & Cms50/72a ${ }^{a}$ & CelA \\
\hline & NZ2565 & U.S.A. & PDDCC & nd & - \\
\hline & NZ2567 & U.S.A. & PDDCC & nd & - \\
\hline & NZ2568 & U.S.A. & PDDCC & nd & - \\
\hline & NZ2569 & U.S.A. & PDDCC & nd & - \\
\hline & NZ2570 & U.S.A. & PDDCC & nd & - \\
\hline & NZ3500 & U.S.A. & PDDCC & nd & - \\
\hline \multicolumn{6}{|c|}{ Rhodococcus fascians } \\
\hline & NZ2596 & U.K. & PDDCC & nd & - \\
\hline & NZ2597 & U.K. & PDDCC & nd & - \\
\hline & NZ2598 & U.K. & PDDCC & nd & - \\
\hline & NZ2599 & U.K. & PDDCC & nd & - \\
\hline & NZ2600 & U.K. & PDDCC & nd & - \\
\hline & NZ2601 & U.K. & PDDCC & nd & - \\
\hline & NZ2602 & U.S.A. & PDDCC & nd & - \\
\hline & NZ2603 & Canada & PDDCC & nd & - \\
\hline & NZ2604 & U.S.A. & PDDCC & nd & - \\
\hline & NZ2605 & U.S.A. & PDDCC & nd & - \\
\hline & NZ5339 & U.K. & PDDCC & nd & - \\
\hline & NZ5340 & U.K. & PDDCC & nd & - \\
\hline & NZ5833 & U.S.A. & PDDCC & nd & - \\
\hline & NZ6788 & New Zealand & PDDCC & nd & - \\
\hline & NZ6792 & New Zealand & PDDCC & nd & - \\
\hline & NZ7109 & Netherlands & PDDCC & nd & - \\
\hline & NZ7113 & Netherlands & PDDCC & nd & - \\
\hline & NZ7261 & New Zealand & PDDCC & nd & - \\
\hline & NZ7364 & New Zealand & PDDCC & nd & - \\
\hline \multicolumn{6}{|c|}{ Streptomyces scabies } \\
\hline & ATCC49173 & New York & ATCC & nd & - \\
\hline & Car 8 & Unknown & R. Loria & nd & - \\
\hline \multicolumn{6}{|c|}{ Pectobacterium carotovora subsp. carotovora } \\
\hline & 028 & North Dakota & NDSU & nd & - \\
\hline \multicolumn{6}{|c|}{ Pectobacterium carotovora subsp. atroseptica } \\
\hline & ECA-6 & North Dakota & NDSU & - & - \\
\hline & ECA-13 & North Dakota & NDSU & nd & - \\
\hline \multicolumn{6}{|c|}{ Staphylococcus aureus } \\
\hline & 84.104 & Unknown & Unknown & nd & - \\
\hline \multirow[t]{2}{*}{ Escherichia coli } & & & & & \\
\hline & ECOLI & Unknown & Unknown & - & - \\
\hline
\end{tabular}

The real-time PCR assay using the CelA primers was also more sensitive than Cms50/72a primers in detecting C. michiganensis subsp. sepedonicus in simulated ring rot infected seed lot experiments conducted in 2006, regardless of the initial population density or colony type of the pathogen (Table 4). When one infected tuber core was blended with 99 healthy tuber cores (1/100), CelA successfully detected the pathogen $75.0 \%$ of the time, while Cms50/72a was effective only $37.5 \%$ of the time. When the infection rates were $1 / 200$ and $1 / 400$, the efficiency of CelA was 37.5 and $62.5 \%$, respectively, while $\mathrm{Cms} 50 / 72 \mathrm{a}$ was 12.5 and $0.0 \%$, respectively (Table 4). Mucoid and nonmucoid type strains were detected with equivalent sensitivity by both CelA and Cms50/72a PCR assays.

Similar results were obtained during simulated BRR infected seed lot experiments conducted in 2007 (Table 5). CelA and $\mathrm{Cms50/72 \textrm {a }}$ real-time assays were similar in the sensitivity of $C$. michiganensis subsp. sepedonicus detection when 1 asymptomatic tuber core was blended with 99 healthy tuber cores, with detection levels of 90.9 and $100 \%$, respectively. However, when asymptomatic to healthy tuber core ratios were $1 / 200$ and $1 / 400$, CelA successfully detected infections 90.9 and $81.8 \%$ of the time, respectively, compared to $\mathrm{Cms} 50 / 72 \mathrm{a}$, in which only 63.6 and $18.2 \%$ of the infections were detected, respectively (Table 5). Again, both primer sets detected mucoid and nonmucoid infections with similar sensitivities. Interestingly, in this experiment, ELISA proved to be more sensitive in detecting asymptomatic infections of the mucoid strain OFF1 compared to IFA. However, ELISA was ineffective in detecting the nonmucoid strain. ELISA was as sensitive as Cms50/72a real-time PCR in detecting asymptomatic mucoid infections at ratios of $1 / 200$ and $1 / 400$. In all simulated seed lot experiments, infection-free cores used as negative controls as well as for diluents of contaminated ratios tested negative by all applicable assays.

In naturally infected seed lots, the CelA real-time PCR assay was also more sensitive than other diagnostic methods in detecting symptomless infections of $\mathrm{C}$. $\mathrm{mi}$ chiganensis subsp. sepedonicus in seed tubers prior to planting (Table 6). Among the seed lots tested, ELISA was ineffective in detecting C. michiganensis subsp. sepedonicus despite ring rot disease levels of $>4 \%$ (Table 6). ELISA only detected the organism in 4 of the 11 ring rot infected certified seed lots, while IFA detected symptomless infections in 7 of 11 seed lots. Real-time PCR using the Cms50/72a and CelA primers detected the ring rot bacterium in 10 of 11 seed lots (Table 6). However, the number of composite samples found to be infected using CelA PCR was proportionately higher than for any 
other test performed in several seed lots with BRR disease development $>4 \%$. Given the extremely high levels of ring rot observed in the field, with BRR infection levels approaching 20\%, CelA was more efficient in detecting symptomless infections. A single false negative resulted with all detection assays in the seed lot with approximately $0.1 \% \mathrm{BRR}$ in the field (Table 6).

\section{DISCUSSION}

The importance of $C$. michiganensis subsp. sepedonicus as a potato pathogen and as a quarantine pest is clearly demonstrated by the volume of research that has been dedicated toward its identification, differentiation, and detection using serological and molecular techniques (2,3,5, 6,9,15-18,20,21,23,25,26,29-32,36-39,46, $48-52,54)$. Not only is this body of re- search impressive by its sheer numbers, it also bridges three decades of work, so it can be assumed that BRR continues to be a globally important pest requiring considerable resources and continuing attention. Much of the reason for this lies in the peculiarities of the disease and the pathogen. BRR is known to remain latent, or symptomless, for long periods of time, thereby permitting the pathogen to go undetected

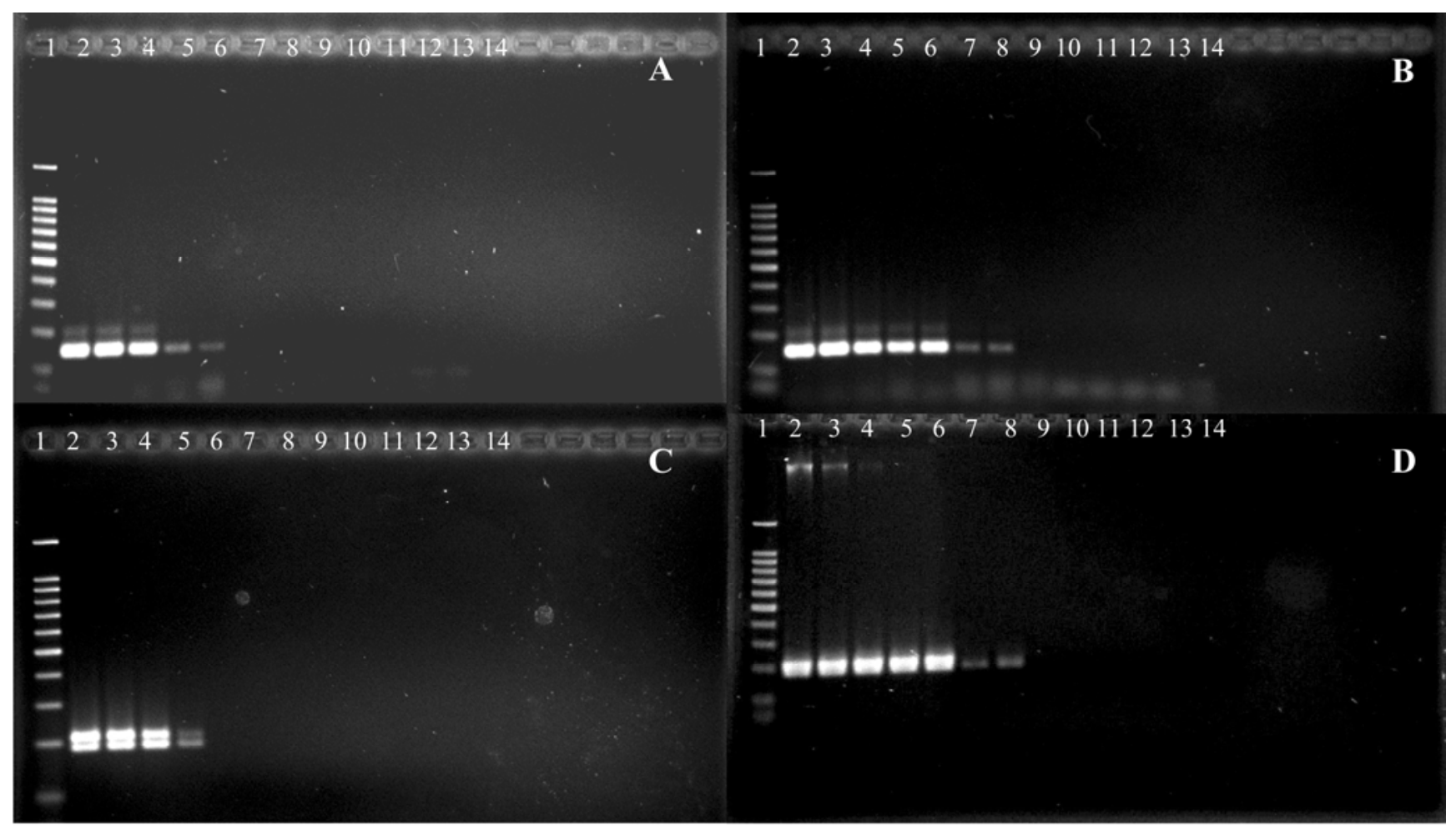

Fig. 1. A, CelA (150 bp) and C, Cms50/72a (double amplicons of 192/213 bp) polymerase chain reaction (PCR) amplicons of serially diluted Clavibacter michiganensis subsp. sepedonicus cells of plasmid positive strain OFF-1 electrophoresed on a 3\% agarose gel. Lane 1, 100-bp Bench top ladder (Promega); lane $2,1 \times 10^{8}$ cells $/ \mathrm{ml}$; lane $3,1 \times 10^{7}$ cells $/ \mathrm{ml}$; lane $4,1 \times 10^{6}$ cells $/ \mathrm{ml} ;$ lane $5,1 \times 10^{5}$ cells $/ \mathrm{ml} ;$ lane $6,1 \times 10^{4}$ cells $/ \mathrm{ml} ;$ lane $7,1 \times 10^{3}$ cells $/ \mathrm{ml} ; 1$ lane 8 , 100 cells $/ \mathrm{ml}$; lane 9, 10 cells $/ \mathrm{ml}$; lane 10, $1.0 \mathrm{cell} / \mathrm{ml}$; lane 11, Pectobacterium carotovora cells; lane 12, water blank. B, CelA (150 bp) and D, Cms50/72a (double amplicons of 192/213 bp) PCR amplicons of serially diluted C. michiganensis subsp. sepedonicus strain OFF-1 DNA electrophoresed on a 2 or $3 \%$

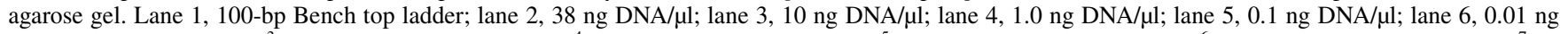
$\mathrm{DNA} / \mu \mathrm{l}$; lane $7,1.0 \times 10^{-3} \mathrm{ng} \mathrm{DNA} / \mu \mathrm{l}$; lane $8,1.0 \times 10^{-4} \mathrm{ng} \mathrm{DNA} / \mu \mathrm{l}$; lane $9,1.0 \times 10^{-5} \mathrm{ng} \mathrm{DNA} / \mu \mathrm{l}$; lane $10,1.0 \times 10^{-6} \mathrm{ng} \mathrm{DNA} / \mu \mathrm{l} ;$ lane $11,1.0 \times 10^{-7} \mathrm{ng}$

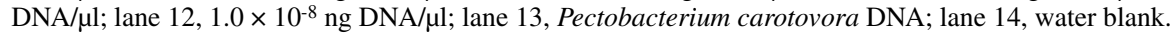
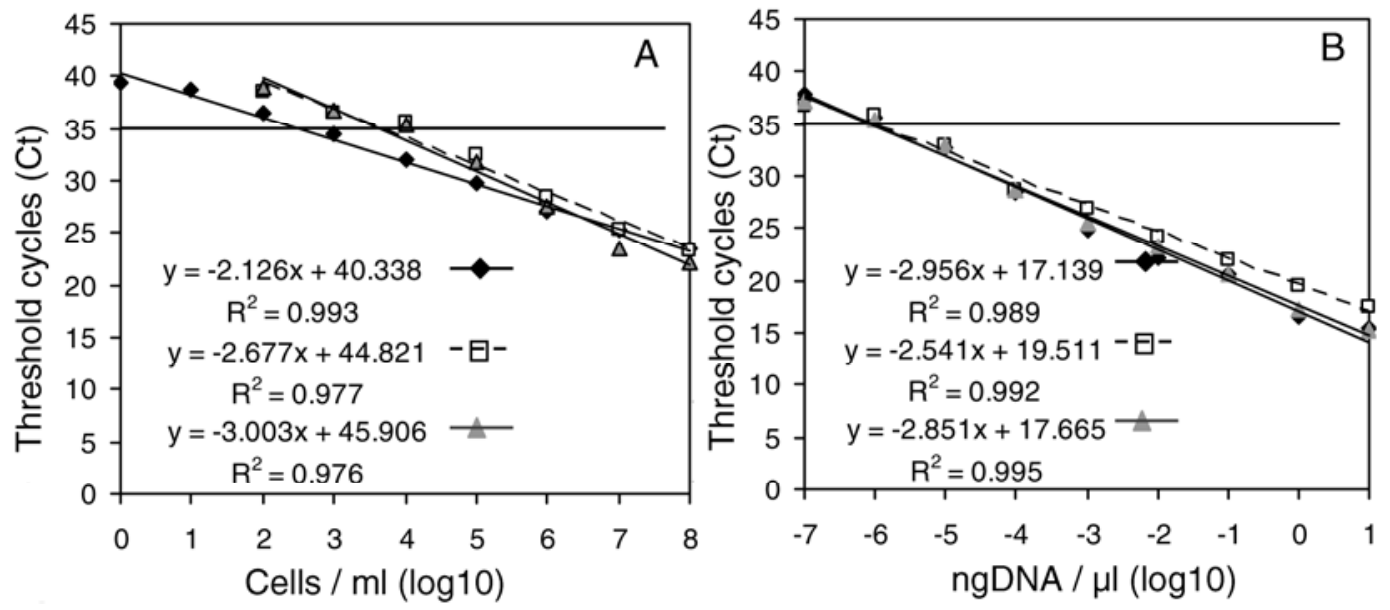

Fig. 2. Sensitivity of CelA (diamond), Cms50 (square), and Cms72a (triangle) polymerase chain reaction (PCR) primers used for detection of Clavibacter michiganensis subsp. sepedonicus bacterial cells (A) and DNA extracted from these bacterial cells (B) of plasmid positive strain OFF-1. Horizontal line represents 35 PCR cycles, the threshold used to make a positive or negative determination. Each data point is the mean of two trials at each concentration of DNA or bacterial cells for each PCR primer. 
and presumably build up inoculum which allows subsequent spread (43). A further complication in the persistence of BRR is that cultivars continue to be developed that do not express disease symptoms in either foliage or tubers $(14,27,34,35)$. Although the absence of disease expression is one means by which the pathogen can go undetected $(34,35)$, seasonal variability in symptom development also occurs among susceptible cultivars in response to environmental conditions (27,33). Regardless of the reason, symptomless infections of $C$. michiganensis subsp. sepedonicus have proven insurmountable in the production of certified seed if visual inspections for the disease are relied upon. Additionally, this pathogen is capable of surviving protracted periods of time as dried slime on potato production surfaces, such as storage walls and equipment, making the pathogen extremely persistent on seed potato farms once they have become infested with the BRR bacterium (42). Noninfected certified seed that comes in contact with contaminated production surfaces can become infected, and the disease cycle begins again. This is particularly important in North America, where most seed is cut before planting, providing ideal infection courts for the ring rot bacterium. The net result is that BRR continues to be a major disease of potato and $C$. michiganensis subsp. sepedonicus remains a globally important quarantine pest, making reliable and highly sensitive methods to detect virulent $C$. michiganensis subsp. sepedonicus in certified seed a critical phase of pathogen and disease control.

Although a great deal of effort has been placed on the unambiguous identification and detection of the ring rot bacterium, there are significant differences in the methodology employed to determine sensi- tivity and specificity of these techniques. Studies on the identification and differentiation of $C$. michiganensis subsp. sepedonicus from other bacteria and bacterial plant pathogens have used in vitro grown bacteria almost exclusively $(2,21,26,32$, 49,51). Additionally, studies to improve detection have also only utilized in vitro grown bacteria (50). Studies designed to detect this pathogen in plant tissue tend to use artificially contaminated, or spiked, potato tissue $(6,37)$ in addition to individual infected potato plants or eggplants $(3,15,20,23,25,29-31,36,48)$. Unfortunately, few studies have been directed at the primary target for $C$. michiganensis subsp. sepedonicus detection technology, that being composite tuber samples $(5,13,16)$. Postharvest testing of certified seed lots for the presence of $C$. michiganensis subsp. sepedonicus is an effective methodology for detecting asymptomatic

Table 4. Sensitivity of real-time polymerase chain reaction (PCR) using Cms50/72a and CelA primers for the detection of asymptomatic Clavibacter michiganensis subsp. sepedonicus infections in artificially produced composite tuber samples in 2006

\begin{tabular}{|c|c|c|c|c|c|c|c|}
\hline \multirow[b]{3}{*}{ Strain type } & \multirow{3}{*}{$\begin{array}{l}\text { IFUb/gram } \\
\text { tuber tissue }\end{array}$} & \multicolumn{6}{|c|}{ Number of asymptomatic tuber cores/total number of cores $^{\mathrm{a}}$} \\
\hline & & \multicolumn{2}{|c|}{ 1/100 } & \multicolumn{2}{|c|}{$1 / 200$} & \multicolumn{2}{|c|}{$1 / 400$} \\
\hline & & Cms50/72a ${ }^{c}$ & CelA $^{c}$ & Cms50/72a ${ }^{c}$ & CelA $^{c}$ & Cms50/72a ${ }^{\mathrm{c}}$ & CelA $^{c}$ \\
\hline \multirow[t]{4}{*}{$\overline{\text { Mucoid }}$} & $1.7 \times 10^{9}$ & $-(38.0 / 39.0)$ & $-(37.8)$ & - $(0 / 0)$ & - $(0)$ & - $(0 / 0)$ & - $(0)$ \\
\hline & $2.0 \times 10^{7}$ & - $(0 / 0)$ & $+(31.0)$ & - $(0 / 0)$ & - $\quad(0)$ & - $(0 / 0)$ & $+(33.1)$ \\
\hline & 0 & $+\quad(28.7 / 30.0)$ & $+\quad(26.1)$ & $+(31.8 / 32.9)$ & - (0) & - $\quad(36.3 / 37.8)$ & $+\quad(34.6)$ \\
\hline & 0 & - $(0 / 0)$ & $+(29.7)$ & - $(0 / 0)$ & $+(30.8)$ & $-\quad(0 / 0)$ & $+(33.9)$ \\
\hline \multirow{4}{*}{ Nonmucoid } & $2.1 \times 10^{10}$ & $+(34.2 / 34 / 6)$ & $+\quad(28.4)$ & $-\quad(35.8 / 36.8)$ & $+(30.3)$ & - $\quad(38.3 / 38.6)$ & $+\quad 33.9)$ \\
\hline & $1.0 \times 10^{7}$ & - $(38.6 / 38 / 9)$ & - $(0)$ & - $(0 / 0)$ & - $(0)$ & - $(0 / 0)$ & - $(0)$ \\
\hline & 0 & $+(31.0 / 32.3)$ & $+(33.9)$ & $-(35.6 / 36.6)$ & $-(35.8)$ & $-(0 / 0)$ & - $(39.4)$ \\
\hline & 0 & - $(36.3 / 37.3)$ & $+(29.2)$ & - $(38.9 / 39.0)$ & $+(31.3)$ & - $(0 / 0)$ & $+(34.6)$ \\
\hline
\end{tabular}

${ }^{a}$ Soak liquid from 100 presumed healthy cores tested negative for immunofluorescent-antibody staining (IFA), enzyme-linked immunosorbent assay (ELISA), as well as PCR with Cms50/72a and CelA. Therefore, healthy tuber soak fluid was included as a negative control for all assays. If a false positive was obtained in these negative samples, the assay was disregarded.

${ }^{b}$ Immunofluorescent units (IFU) per gram of tuber tissue. Tuber cores were soaked following standard protocols and supernatant was assayed.

${ }^{\mathrm{c}}$ Positive or negative detection of $C$. michiganensis subsp. sepedonicus denoted as +/-, respectively. Mean crossing threshold values (Ct) of two assays are in parentheses. Samples with Ct values greater than 35 were considered negative.

Table 5. Sensitivity of real-time polymerase chain reaction (PCR) using Cms50/72a and CelA primers for the detection of asymptomatic Clavibacter michiganensis subsp. sepedonicus infections in artificially produced composite tuber samples in 2007

\begin{tabular}{|c|c|c|c|c|c|c|c|c|c|c|c|c|c|}
\hline \multirow[b]{3}{*}{ Strain type } & \multirow{3}{*}{$\begin{array}{l}\text { IFU } / \text { /gram } \\
\text { tuber tissue }\end{array}$} & \multicolumn{12}{|c|}{ Number of asymptomatic tuber cores/total number of cores ${ }^{a}$} \\
\hline & & \multicolumn{4}{|c|}{$1 / 100$} & \multicolumn{4}{|c|}{$1 / 200$} & \multicolumn{4}{|c|}{$1 / 400$} \\
\hline & & IFA $^{\mathbf{c}}$ & ELISA $^{\mathbf{d}}$ & Cms50/72a ${ }^{e}$ & CelA ${ }^{\mathrm{e}}$ & IFA $^{\mathbf{c}}$ & ELISA $^{\mathbf{d}}$ & Cms50/72a ${ }^{e}$ & CelA $^{\mathrm{e}}$ & $\mathbf{I F A}^{\mathbf{c}}$ & ELISA $^{d}$ & Cms50/72a ${ }^{e}$ & CelA $^{\mathrm{e}}$ \\
\hline \multirow[t]{6}{*}{ Mucoid } & $4.7 \times 10^{7}$ & - & $+(0.303)$ & $+(28.0 / 28.6)$ & $+(23.8)$ & + & $+(0.359)$ & $+(31.2 / 32.4)$ & $+(25.6)$ & - & $+(0.345)$ & $-(35.2 / 36.7)$ & $+(29.7)$ \\
\hline & $3.3 \times 10^{7}$ & - & $+(0.448)$ & $+(29.5 / 30.7)$ & $+(27.1)$ & + & $+(0.392)$ & $+(33.5 / 34.7)$ & $+(29.1)$ & + & $+(0.445)$ & $-(36.5 / 38.0)$ & $+(33.8)$ \\
\hline & $7.6 \times 10^{6}$ & - & $+(0.211)$ & $+(33.0 / 34.1)$ & $+(32.5)$ & - & $-(0.156)$ & $-(35.5 / 36.7)$ & $-(35.2)$ & - & $-(0.149)$ & - $(39.8 / 0)$ & - (38.7) \\
\hline & $3.1 \times 10^{6}$ & - & $+(0.241)$ & $+(32.8 / 34.0)$ & $+(31.2)$ & - & $-(0.160)$ & $-(36.1 / 36.4)$ & $+(33.2)$ & - & $-(0.161)$ & $-(37.8 / 38.4)$ & $-(36.7)$ \\
\hline & $1.5 \times 10^{5}$ & + & $+(0.266)$ & $+(31.5 / 32.3)$ & $+(31.3)$ & - & - (0.189) & $+(33.3 / 34.1)$ & $+(32.1)$ & - & $-(0.176)$ & $-(36.2 / 36.6)$ & $+(34.3)$ \\
\hline & 0 & - & $+(0.456)$ & $+(33.0 / 34.1)$ & $+(31.6)$ & + & $+(0.403)$ & $-(36.0 / 37.1)$ & $+(32.7)$ & - & $+(0.385)$ & $-(37.8 / 38.5)$ & $+(34.2)$ \\
\hline \multirow[t]{5}{*}{ Nonmucoid } & $8.1 \times 10^{8}$ & - & $-(0.121)$ & $+(30.9 / 32.6)$ & $+(24.0)$ & - & $-(0.112)$ & $+(32.9 / 34.2)$ & $+(25.0)$ & - & - (0.112) & $-(35.6 / 37.3)$ & $+(30.3)$ \\
\hline & $5.0 \times 10^{7}$ & - & $-(0.136)$ & $+(31.3 / 33.0)$ & $+(25.2)$ & + & $-(0.111)$ & $+(33.6 / 34.8)$ & $+(27.3)$ & + & $-(0.106)$ & $-(36.8 / 37.4)$ & $+(31.0)$ \\
\hline & $2.2 \times 10^{7}$ & - & $-(0.110)$ & $+(30.0 / 31.8)$ & $+(26.8)$ & - & $-(0.103)$ & $+(31.6 / 32.6)$ & $+(28.7)$ & - & $-(.0104)$ & $+(33.7 / 34.0)$ & $+(32.6)$ \\
\hline & $3.0 \times 10^{6}$ & - & $-(0.115)$ & $+(32.5 / 33.4)$ & $+(29.9)$ & + & $-(0.105)$ & $-(36.3 / 36.0)$ & $+(32.2)$ & - & $-(0.103)$ & $-(38.3 / 38.8)$ & $+(34.0)$ \\
\hline & 0 & - & $-(0.108)$ & $+(30.1 / 31.8)$ & $+(30.6)$ & - & $-(0.110)$ & $+(32.2 / 33.3)$ & $+(33.0)$ & - & $-(0.106)$ & $-(37.0 / 38.3)$ & $+(34.5)$ \\
\hline
\end{tabular}

a Soak liquid from 100 presumed healthy cores tested negative for immunofluorescent-antibody staining (IFA), enzyme-linked immunosorbent assay (ELISA), as well as PCR with Cms50/72a and CelA. Therefore, healthy tuber soak fluid was included as a negative control for all assays. If a false positive was obtained in these negative samples the assay was disregarded.

${ }^{\mathrm{b}}$ Immunofluorescent units (IFU) per gram of tuber tissue. Tuber cores were soaked following standard protocols and supernatant was assayed. Tuber cores with zero IFU/g were tested via PCR with Cms50/72a and CelA to ensure infection by C. michiganensis subsp. sepedonicus had taken place.

${ }^{\mathrm{c}}$ Samples with greater than $5 \mathrm{IFU} /$ microscope field (MF) were considered positive.

${ }^{\mathrm{d}}$ Mean absorbance values at $405 \mathrm{~nm}$ of triplicate wells is in parentheses. Samples with absorbance values greater than 0.2 at $405 \mathrm{~nm}$ were considered positive. Mean absorbance values for the positive and negative controls were 0.458 and 0.103 , respectively.

${ }^{\text {e }}$ Positive or negative detection of C. michiganensis subsp. sepedonicus denoted as +/-, respectively. Mean crossing threshold values (Ct) of two assays are in parentheses. Samples with $\mathrm{Ct}$ values greater than 35 were considered negative. 
infections of the ring rot bacterium, a procedure first suggested by De Boer $(11,13)$. However, potato stems collected during the growing season can also be used to detect asymptomatic infections (23). Early postharvest testing studies were directed at determining the performance of serological methods such as ELISA and IFA $(13,16)$, methods that are still recommended and employed today $(1,12)$. While our research group has made a previous effort to develop PCR technology to improve detection sensitivity (5), ring rot infections in certified seed lots continue, indicating that more research is needed. Studies reported here clearly demonstrate that the real-time CelA PCR assay developed by our laboratory is robust compared to several other standard detection technologies for this pathogen. We believe this is the first time a C. michiganensis subsp. sepedonicus detection method has been developed from the onset with the primary objective of improving the detection of the ring rot bacterium in composite tuber samples.

The CelA primers reported here are specific to C. michiganensis subsp. sepedoni$c u s$, and we found no evidence that they will cross-react with any other potato pathogen or gram-positive plant pathogenic actinomycete. The data generated during these studies clearly demonstrate that the CelA primers are more sensitive than standard postharvest tests using monoclonal antibodies in ELISA and IFA $(17,18)$. The CelA primers also proved to have greater sensitivity in the detection of symptomless $C$. michiganensis subsp. sepedonicus infection in composite seed lots compared to Cms50/72a with few exceptions. The Cms50/72 primers (37) are among the most widely used PCR primers to detect latent infections of the ring rot bacterium. The CelA primers detected C. michiganensis subsp. sepedonicus in artificially contaminated seed lots and in naturally occurring certified seed lots that were known to have been exposed to the pathogen with greater sensitivity than other detection methods. The CelA real-time PCR assay was as sensitive in detecting $C$. michiganensis subsp. sepedonicus in $1 / 400$ composite tuber samples as other methods were in successfully detecting the ring rot bacterium in $1 / 100$ or 1/200 composites. The CelA primers were frequently the only detection technology that successfully detected a symptomless infection after seed lots were monitored in the field during the growing season. Clearly, the CelA primers reported here have an advantage for use in postharvest testing compared to the current recommended methods (1,12). Furthermore, since 200 tuber composites are the global standard for seed lot indexing $(1,12)$, realtime PCR assay using CelA should be an improvement over existing technology at composite sample numbers of 400, which could dramatically reduce the costs associ- ated with such testing. There are a number of additional studies that need to be performed to enhance the utility of the CelA real-time PCR format to optimize the assay for the detection of asymptomatic infections. The CelA primers should either be multiplexed with Cms50/72a primers (37) to reduce the potential for false positives, or an internal reaction control can be integrated into the TaqMan PCR assay (55) in order to minimize false negative results.

During the course of these studies, we attempted to produce artificially infected composite tuber samples that were infected with differing levels of the target bacterium. We attempted to do this by quantifying the level of $C$. michiganensis subsp. sepedonicus in the BRR-infected tubers using IFA and selecting those infected tuber cores that had low to high levels of ring rot bacteria prior to blending them with healthy tuber cores. Although we were generally successful in achieving our goal of producing artificially infected composite tuber samples that differed in the level of $C$. michiganensis subsp. sepedonicus, there were notable exceptions (Table 4). In a few specific cases, high levels of $C$. michiganensis subsp. sepedonicus in infected tuber cores, as determined by IFA, were blended with healthy tuber cores, and the resulting PCR tests were negative for the pathogen. Conversely, in the same experiment, tuber cores that were IFA negative but PCR positive, which we interpreted as a low infection, tested positive with PCR. These incongruities are difficult to explain but may be due in part to the difficulties that can exist when bacterial cells adhere to tuber tissue and are obscured during microscopic examination of the IFA slides, which has been previously discussed $(3,23)$. In other cases, the incongruity of these results may be due also to the presence of inhibitors to the PCR reaction that are known to exist in tuber tissue. Inhibitors to the PCR reaction have been previously reported and discussed in conjunction with $C$. michiganensis subsp. sepedonicus detection $(5,52)$. Nonetheless, we do not believe these minor flaws in data set detract from the overall results we obtained, which clearly indicate real-time PCR is superior to serological techniques such as ELISA or IFA for the detection of symptomless infections of $C$. michiganensis subsp. sepedonicus. However, they do illustrate a potential pitfall of this type of testing and the care that must be taken to reduce or eliminate potential inhibitors to the PCR reaction.

It is clear from the data in studies reported here that ELISA is ineffective in detecting symptomless infections of $C$. michiganensis subsp. sepedonicus when indexing seed lots. In controlled experiments, ELISA was effective in detecting symptomless infections only when composite samples of $1 / 100$ were used and only with mucoid strains of the pathogen. When certified seed lots known to be exposed to $C$. michiganensis subsp. sepedonicus were indexed in 2006, ELISA only detected the pathogen in four of the seed lots tested, whereas IFA, Cms50/72, and CelA detected $C$. michiganensis subsp. sepedonicus in 7, 10, and 10 seedlots, re-

Table 6. Indexing of certified seed potatoes exposed to bacterial ring rot (BRR) in 2006 ${ }^{\mathrm{a}}$

\begin{tabular}{lcllccc}
\hline & & \multicolumn{5}{c}{ Results of testing (no. positive/no. tested) } \\
\cline { 3 - 7 } Seed farm & Seed lot & ELISA (abs) & IFA & Cms50/72a & CelA & BRR $(\boldsymbol{\%})^{\mathbf{d}}$ \\
\hline $\mathrm{A}$ & 1 & $0 / 19(0.008-0.029)$ & $0 / 19$ & $0 / 19$ & $0 / 19$ & 0 \\
$\mathrm{~A}$ & 2 & $0 / 20(0.002-0.012)$ & $0 / 20$ & $0 / 20$ & $0 / 20$ & 0 \\
$\mathrm{~A}$ & 3 & $2 / 21(0.010-0.291)$ & $2 / 21$ & $2 / 21$ & $2 / 21$ & $4.5-6.0$ \\
$\mathrm{~A}$ & 4 & $0 / 20(0.007-0.019)$ & $0 / 20$ & $0 / 20$ & $0 / 20$ & 0 \\
$\mathrm{~B}$ & 1 & $0 / 19(0.001-0.010)$ & $0 / 19$ & $0 / 19$ & $0 / 19$ & 0.1 \\
$\mathrm{~B}$ & 2 & $0 / 20(0.006-0.054)$ & $1 / 20$ & $5 / 20$ & $13 / 19$ & $8.5-10.0$ \\
$\mathrm{~B}$ & 3 & $0 / 16(0.001-0.008)$ & $0 / 16$ & $0 / 16$ & $0 / 16$ & 0 \\
$\mathrm{~B}$ & 4 & $0 / 19(0.002-0.011)$ & $0 / 19$ & $1 / 19$ & $1 / 19$ & 0 \\
$\mathrm{~B}$ & 5 & $0 / 19(0.008-0.014)$ & $0 / 19$ & $0 / 19$ & $0 / 19$ & 0 \\
$\mathrm{~B}$ & 6 & $0 / 22(0.002-0.035)$ & $0 / 22$ & $0 / 22$ & $0 / 22$ & 0 \\
$\mathrm{C}$ & 1 & $0 / 22(0.001-0.028)$ & $0 / 22$ & $1 / 22$ & $5 / 22$ & $6.5-8.0$ \\
$\mathrm{C}$ & 2 & $1 / 10(0.001-0.331)$ & $1 / 10$ & $4 / 10$ & $7 / 10$ & $15-29$ \\
$\mathrm{C}$ & 3 & $1 / 22(0.008-0.330)$ & $1 / 22$ & $3 / 22$ & $3 / 22$ & $5-6$ \\
$\mathrm{C}$ & 4 & $1 / 16(0.012-0.331)$ & $1 / 16$ & $1 / 16$ & $1 / 16$ & $6-8$ \\
$\mathrm{C}$ & 5 & $0 / 20(\mathrm{NA})$ & $2 / 20$ & $6 / 20$ & $13 / 20$ & $4-6$ \\
$\mathrm{C}$ & 6 & $0 / 20$ (NA) & $0 / 20$ & $8 / 20$ & $14 / 20$ & $17-20$ \\
$\mathrm{C}$ & 7 & $0 / 20$ (NA) & $1 / 20$ & $1 / 20$ & $5 / 20$ & $6-9$ \\
\hline
\end{tabular}

${ }^{a}$ Healthy tuber soak fluid was included as a negative control for all assays. If a false positive was obtained is these negative samples the assay was disregarded.

${ }^{b}$ Numbers of tubers submitted for BRR testing varied from 3,200 to 4,400 per seed lot. Tests for the presence of Clavibacter michiganensis subsp. sepedonicus were performed on stem end cores taken from 200 tubers per composited sample.

${ }^{c}$ Numbers of enzyme-linked immunosorbent assay (ELISA) positives per number of composites tested. Range of absorbance values at $405 \mathrm{~nm}$ is in parentheses. Samples with absorbance values greater than 0.2 at $405 \mathrm{~nm}$ were considered positive. Mean absorbance values for positive and negative controls were 0.576 and 0.043 , respectively.

${ }^{d}$ Estimated percentage of BRR expressed in the field the year following laboratory testing. A minimum of 1,000 plants were rated for symptoms. 
spectively. The number of composite tuber samples that tested positive with CelA versus the other diagnostic tests was also substantially higher, which is further evidence that these primers are very robust when used in a real-time PCR format. Although the potato growers involved in this portion of the study were cautioned against using these seed lots in the production of their crop, they chose to do so because of potato seed shortages. The high incidence of BRR observed in the fields grown with this seed was undoubtedly due to the seed cutting and handling procedures employed by these growers. However, the fact remains that CelA real-time PCR was the only method that was able to detect potentially high infection rates in these seedlots compared to the other diagnostic methodologies used during this portion of our studies.

The cellulase A virulence gene sequence is on the plasmid of the $C$. michiganensis subsp. sepedonicus strain that was genome sequenced (7). However, not all strains have a plasmid $(40,41)$. Early studies demonstrated that pCS1 and a repeated sequence from this plasmid were highly conserved with approximately 1.26 to 1.5 copies in each $C$. michiganensis subsp. sepedonicus strain depending on whether or not it is integrated into the chromosome or episomal, respectively. This repeated sequence was the target of early attempts to improve detection with either DNA hybridization or PCR $(20,54)$, but those early diagnostic methods proved to be no more sensitive than serological assays employed at the time. One of the initial concerns in the development of the CelA primers for $C$. michiganensis subsp. sepedonicus detection was the fact that the cellulase pathogenicity genes are present on the plasmid pCS1 (7), and this native plasmid may either be autonomous or in integrated form $(39,41)$. Although rare, there are two strains of $C$. michiganensis subsp. sepedonicus in which pCS1 is not present either episomally or integrated, P45 and CS14 (41). Strain P45 has received considerable attention as a result $(28,45)$. It has been suggested that the P45 strain lost its native plasmid after nearly 40 years of subculturing (53). Strain CS14, originally recovered from infected potato tubers from Montana, has been in our collection for nearly 30 years and was obtained from two independent sources. Our initial concern was that strains such as P45 and CS14 would not be detected by the CelA primers described here, a phenomenon noted during the development of other pCS1-based DNA probes (40) and PCR primers (53). Results of the studies reported here confirm our initial concern that the CelA PCR primers do not detect strains P45 and CS14, which have been reported as avirulent (41). However, it should be noted that our P45 culture, originally obtained many years ago from S. H. De Boer, has been demonstrated to contain pCS1 (50). If the results of that research were correct, we would expect the CelA primer to detect strain P45, but they did not. There is no evidence we are aware of that suggests that strains such as P45 and CS14 exist in nature, and we are inclined to agree with previous investigators (53) that these strains are anomalies created by many years of subculturing. Indeed, the screening of numerous strains from our culture collection and 4 years of field testing natural infections have led us to believe that the CelA primers described here are specific to virulent $C$. michiganensis subsp. sepedonicus with improved sensitivity. The ability of CelA primers to detect $C$. michiganensis subsp. sepedonicus strains that are plasmid negative indicates that the CelA gene is integrated into the chromosomes of naturally occurring plasmid negative strains. Mogen et al. (41) found pCS1 either free or integrated in the form of a repeated sequence in most strains of $C$. michiganensis subsp. sepedonicus, causing the authors to speculate that the repeated sequence must serve some important function for the pathogen that was at the time unknown. It is likely that function is pathogenicity, but that can only be confirmed with further genome sequencing of $C$. michiganensis subsp. sepedonicus strains known to be negative for pCS1.

This is the first study we are aware of that compares the sensitivity of two serological and two PCR methods in the detection of C. michiganensis subsp. sepedonicus in composite tuber samples. We were careful to use large sample sizes, usually 4,000 tubers per seed lot, when testing certified seed lots that had been exposed naturally to $C$. michiganensis subsp. sepedonicus. These samples sizes are consistent with those recommended in a statistical analysis performed by Clayton and Slack (10) specifically with BRR in mind. Despite using large sample sizes, ELISA and IFA were ineffective in detecting latent C. michiganensis subsp. sepedonicus infections in several seed lots, even though the grow outs of these seed sources demonstrated relatively high infection rates. Since ELISA and IFA demonstrated low frequencies of detection in composite samples, relative to CelA or Cms50/72 PCR, we recommend that real-time PCR technology be used as the primary screening tool when indexing certified seed lots for the presence of $C$. michiganensis subsp. sepedonicus.

\section{ACKNOWLEDGMENTS}

The authors gratefully acknowledge funding received by USDA-ARS SCA 58-5354-7-541 and the Manitoba Seed Potato Growers Association. The assistance of J. Crosslin is also gratefully acknowledged.

\section{LITERATURE CITED}

1. Anonymous. 2006. Clavibacter michiganensis subsp. sepedonicus. EPPO Bull. 36:99-109.

2. Bach, H. J., Jessen, I., Schloter, M., and
Munch, J. C. 2003. A TaqMan-PCR protocol for quantification and differentiation of the phytopathogenic Clavibacter michiganensis subsp. sepedonicus. J. Microbiol. Methods 52:85-91.

3. Baer, D., and Gudmestad, N. C. 1993. Serological detection of nonmucoid strains of Clavibacter michiganensis subsp. sepedonicus in potato. Phytopathology 83:157-163.

4. Baer, D., and Gudmestad, N. C. 1995. In vitro cellulolytic activity of the plant pathogen Clavibacter michiganensis subsp. sepedonicus. Can. J. Microbiol. 41:877-888.

5. Baer, D., Mitzel, E., Pasche, J., and Gudmestad, N. C. 2001. PCR detection of Clavibacter michiganensis subsp. sepedonicus-infected tuber samples in a plate capture assay. Am. J. Potato Res. 78:269-277.

6. Beckhoven, J. R. C. M. v., Stead, D. E., and van der Wolf, J. M. 2002. Detection of Clavibacter michiganensis subsp. sepedonicus by AmpliDet RNA, a new technology based on real time monitoring of NASBA amplicons with a molecular beacon. J. Appl. Microbiol. 93:840-849.

7. Bentley, S. D., Corton, C., Brown, S. E., Barron, A., Clark., L., Doggett, J., Harris, B., Ormond, D., Quail, M. A., May, G., Francis, D., Knudson, D., Parkhill, J., and Ishimaru, C. A 2008. Genome of the actinomycete plant pathogen Clavibacter michiganensis subsp. sepedonicus suggests recent niche adaptation. J. Bacteriol. 190:2150-2160.

8. Bishop, A. L., and Slack, S. A. 1987. Effect of cultivar, inoculum dose, and strain of Clavibacter michiganense subsp. sepedonicum on symptom development in potatoes. Phytopathology 77:1085-1089.

9. Brown, S. E., Reilley, A. A., Dnudson, D. L., and Ishimaru, C. A. 2002. Genomic fingerprinting of virulent and avirulent strains of Clavibacter michiganensis subspecies sepedonicus. Curr. Microbiol. 44:112-119.

10. Clayton, M. K., and Slack, S. A. 1988. Sample size determination in zero tolerance circumstances and the implications of stepwise sampling: Bacterial ring rot as a special case. Am Potato J. 65:711-723.

11. De Boer, S. H. 1991. Current status and future prospects of bacterial ring rot testing. Am. Potato J. 68:107-113.

12. De Boer, S. H., Charkowski, A. O., Zink, R. T., Martinez-Soriano, J. P., and Flores-Olivas, A 2005. Procedure for detection and identification of Clavibacter michiganensis subsp. sepedonicus (Spieckermann and Kotthoff) Davis, Gillaspie, Vidaver and Harris, in potato ( $\mathrm{So}$ lanum tuberosum L.) tubers. Rev. Mex. Fitopatol. 23:329-334.

13. De Boer, S. H., De Haan, T.-L., and Mawhinney, J. 1989. Predictive value of post harvest serological tests for bacterial ring rot of potato. Can. J. Plant Pathol. 11:317-321.

14. De Boer, S. H., and McCann, M. 1990. Detection of Corynebacterium sepedonicum in potato cultivars with different propensities to express ring rot symptoms. Am. Potato J. 67:685694.

15. De Boer, S. H., and McNaughton, M. E. 1986. Evaluation of immunofluorescence with monoclonal antibodies for detecting latent bacterial ring rot infections. Am. Potato J. 63:533543.

16. De Boer, S. H., Stead, D. E., Alivizatos, A. S., Janse, J. D., van Vaerenbergh, J., De Haan, T. L., and Mawhinney, J. 1994. Evaluation of serological tests for detection of Clavibacter michiganensis subsp. sepedonicus in composite potato stem and tuber samples. Plant Dis. 78:725-729.

17. De Boer, S. H., and Wieczorek, A. 1984. Production of monoclonal antibodies to Corynebacerium sepedonicum. Phytopathology 74:14311434. 
18. De Boer, S. H., Wieczorek, A., and Kummer, A. 1988. An ELISA test for bacterial ring rot of potato with a new monoclonal antibody. Plant Dis. 72:874-878.

19. Dineson, I. G., and De Boer, S. H. 1995. Extraction of Clavibacter michiganensis subsp. sepedonicus composite samples of potato tubers. Am. Potato J. 72:133-142.

20. Drennan, J. L., Westra, A. A. G., Slack, S. A., Delserone, L. M., Collmer, A., Gudmestad, N. C., and Oleson, A. E. 1993. Comparison of a DNA hybridization probe and ELISA for the detection of Clavibacter michiganensis subsp. sepedonicus in field-grown potatoes. Plant Dis. 77:1243-1247.

21. Firrao, G., and Locci, R. 1994. Identification of Clavibacter michiganensis subsp. sepedonicus using the polymerase chain reaction. Can. J. Microbiol. 40:148-151.

22. Gartemann, K.-H., Abt, B., Bekel, T., Burger, A., Engemann, J., Flugel, M., Gaigalat, L., Goesmann, A., Grafen, I., Kalinowski, J., Kaup, O., Kirchner, O., Krause, L., Linke, B., McHardy, A., Meyer, F., Pohle, S., Ruckert, C., Schneiker, S., Zellermann, E., Puhler, A., Eichenlaub, R., Kaiser, O., and Bartels, D. 2008. The genome sequence of the tomatopathogenic actinomycete Clavibacter michiganensis subsp. michiganensis NCPPB382 reveals a large island involved in pathogenicity. J. Bacteriol. 190:2138-2149.

23. Gudmestad, N. C., Baer, D., and Kurowski, C. J. 1991. Validating immunoassay test performance in the detection of Corynebacterium sepedonicum during the growing season. Phytopathology 81:475-480.

24. Henningson, P. J., and Gudmestad, N. C. 1992. Comparison of exopolysaccharides from mucoid and nonmucoid strains of Clavibacter michiganensis subsp. sepedonicus. Can. J. Microbiol. 39:291-296.

25. Hu, X., Lai, F.-M., Reddy, A. S. N., and Ishimaru, C. A. 1995. Quantitative detection of Clavibacter michiganensis subsp. sepedonicus by competitive polymerase chain reaction. Phytopathology 85:1468-1473.

26. Johansen, I. E., Rasmussen, O. F., and Heide, M. 1989. Specific identification of Clavibacter michiganensis subsp. sepedonicum by DNAhybridization probes. Phytopathology 79:10191023.

27. Kawchuk, L. M., Lynch, D. R., Kozub, G. C., Nelson, G. A., Kulcsar, F., and Fujimoto, D. K. 1998. Multi-year evaluation of Clavibacter michiganensis subsp. sepedonicus disease symptoms in cultivated potato genotypes. Am. J. Potato Res. 75:235-243.

28. Laine, M. J., Haapalainen, M., Wahlroos, T., Kankare, K., Nissinen, R., Kassuwi, S., and Metzler, M. C. 2000. The cellulase encoded by the native plasmid of Clavibacter michiganensis subsp. sepedonicus plays a role in virulence and contains an expansin-like domain. Physiol. Mol. Plant Pathol. 57:221-233.

29. Lee, I.-M., Bartoszyk, I. M., Gundersen, D. E., Mogen, B., and Davis, R. E. 1997. Nested PCR for ultrasensitivie detection of the potato ring rot bacterium, Clavibacter michiganensis subsp. sepedonicus. Appl. Environ. Microbiol. 63:2625-2630.

30. Lee, I.-M., Lukaesko, L. A., and Maroon, C. J. M. 2001. Comparison of dig-labeled PCR, nested PCR, and ELISA for the detection of Clavibacter michiganensis subsp. sepedonicus in field-grown potatoes. Plant Dis. 85:261-266.

31. Li, X., and De Boer, S. H. 1995. Selection of polymerase chain reaction primers from an RNA intergenic spacer region for specific detecion of Clavibacter michiganensis subsp. sepedonicus. Phytopathology 85:837-842.

32. Louws, F. J., Bell, J., Medina-Mora, C. M., Smart, C. D., Opgenorth, D., Ishimaru, C. A., Hausbeck, M. K., de Bruijn, F. J., and Fulbright, D. W. 1998. rep-PCR-mediated genomic fingerprinting: A rapid and effective method to identify Clavibacter michiganensis. Phytopathology 88:862-868.

33. Manzer, F. E., Gudmestad, N. C., and Nelson, G. A. 1987. Factors affecting infection, disease development and symptom expression of bacterial ring rot. Am. Potato J. 64:671-675.

34. Manzer, F. E., and Kurowski, C. J., Jr. 1992. Bacterial ring rot disease development in resistant and susceptible cultivars. Am. Potato J. 69:363-370.

35. Manzer, F. E., and McKenzie, A. R. 1988. Cultivar response to bacterial ring rot infection in Maine. Am. Potato J. 65:333-339.

36. Mills, D., and Russell, B. W. 2003. Parameters for specific detection of Clavibacter michiganensis subsp. sepedonicus in potato stems and tubers by multiplexed PCR-ELISA. Am. J. Potato Res. 80:223-234.

37. Mills, D., Russell, B. W., and Hanus, J. W. 1997. Specific detection of Clavibacter michiganensis subsp. sepedonicus by amplification of three unique DNA sequences isolated by subtraction hybridization. Phytopathology 87:853-861.

38. Mirza, M. S., Rademaker, J. L. W., Janse, J. D., and Akkermans, A. D. L. 1993. Specific 16s ribosomal RNA targeted oligonucleotide probe against Clavibacter michiganensis subsp. sepedonicus. Can. J. Microbiol. 39:1029-1034.

39. Mogen, B. D., Gudmestad, N. C., and Oleson, A. E. 1987. Evaluation of a cloned sequence from Corynebacterium sepedonicum for use as a pathogen-specific DNA hybridization probe. (Abstr.) Phytopathology 77:1693.

40. Mogen, B. D., and Oleson, A. E. 1987. Homology of pCS1 plasmid sequences with chromosomal DNA in Clavibacter michiganensis subsp. sepedonicus: Evidence for the presence of a repeated sequence and plasmid integration. Appl. Environ. Microbiol. 53:24762481

41. Mogen, B. D., Oleson, A. E., Sparks, R. B., Gudmestad, N. C., and Secor, G. A. 1988. Distribution and partial characterization of pCS1, a highly conserved plasmid present in Clavibacter michiganense subsp. sepedonicum. Phytopathology 78:1381-1386.

42. Nelson, G. A. 1980. Long-term survival of Corynebacterium sepedonicum on contaminated surfaces and in infected potato stems. Am. Potato J. 57:595-600.

43. Nelson, G. A. 1982. Corynebacterium sepedonicum in potato: Effect of inoculum concentration on ring rot symptoms and latent infection. Can. J. Plant Pathol. 4:129-133.

44. Nelson, G. A., and Kozub, G. C. 1983. Effect of total light energy on symptoms and growth of ring rot-infected Red Pontiac potato plants. Am. Potato J. 60:461-468.
45. Nissinen, R., Kassuwi, S., Peltola, R., and Metzler, M. C. 2001. In planta-complementation of Clavibacter michiganensis subsp. sepedonicus strains deficient in cellulase production or HR induction restores virulence. Eur. J. Plant Pathol. 107:175-182.

46. Palomo, J. L., Velazquez, E., Mateos, P. F., Garcia-Benavides, P., and Martinez-Molina, E. 2000. Rapid identification of Clavibacter michiganensis subsp. sepedonicus based on the stable low molecular weight RNA (LMW RNA) profiles. Eur. J. Plant Pathol. 106:789793.

47. Pankova, I., and Kokoskova, B. 2002. Sensitivity and specificity of monoclonal antibody $\mathrm{Mn}$ Cs1 for detection and determination of Clavibacter michiganensis subsp. sepedonicus, the causal agent of bacterial ring rot of potato. Plant Prot. Sci. 38:117-124.

48. Pastrik, K. H. 2000. Detection of Clavibacter michiganensis subsp. sepedonicus in potato tubers by multiplex PCR and coamplification of host DNA. Eur. J. Plant Pathol. 106:155165.

49. Pastrik, K. H., and Rainey, F. A. 1999. Identification and differentiation of Clavibacter michiganensis subspecies by polymerase chain reaction-based techniques. J. Phytopathol 147:687-693.

50. Rademaker, J. L. W., and Janse, J. D. 1994 Detection and identification of Clavibacter michiganensis subsp. sepedonicus and Clavibacter michiganensis subsp. michiganensis by nonradioactive hybridization, polymerase chain reaction, and restriction enzyme analysis. Can. J. Microbiol. 40:1007-1018.

51. Rivas, R., Velaquez, E., Palomo, J. L., Mateos, P. F., Garcia-Benavides, P., and MartinezMolina, E. 2002. Rapid identification of Clavibacter michiganensis subsp. sepedonicus using two primers random amplified polymorphic DNA (TP-RAPD) fingerprints. Eur. J. Plant Pathol. 108:179-184.

52. Schaad, N. W., Berthier-Schaad, Y., Sechler, A., and Knorr, D. 1999. Detection of Clavibacter michiganensis subsp. sepedonicus in potato tubers by BIO-PCR and an automated realtime fluorescence detection system. Plant Dis. 83:1095-1100.

53. Schneider, B. J., Zhao, J. L., and Orser, C. S 1993. Detection of Clavibacter michiganensis subsp. sepedonicus by DNA amplification. FEMS Microbiol. Lett. 109:207-212.

54. Slack, S. A., Drennan, J. L., Westra, A. A. G. Gudmestad, N. C., and Oleson, A. E. 1996. Comparison of PCR, ELISA, and DNA hybridization for the detection of Clavibacter michiganensis subsp. sepedonicus in field-grown potatoes. Plant Dis. 80:519-524.

55. Smith, D. S., De Boer, S. H., and Gourley, J. 2008. An internal reaction control for routine detection of Clavibacter michiganensis subsp. sepedonicus using a real-time TaqMan PCRbased assay. Plant Dis. 92:684-693.

56. Wang, A., and Lazarovits, G. 2004. Enumeration of plant pathogenic Streptomyces on post harvest potato tubers under storage conditions. Can J. Plant Pathol. 26:563-572.

57. Westra, A. A. G., and Slack, S. A. 1992. Isolation and characterization of extracellular polysaccharide of Clavibacter michiganensis subsp. sepedonicus. Phytopathology 82:1193-1199. 